OPEN ACCESS

Edited by:

Eric Boué-Grabot,

Université de Bordeaux, France

Reviewed by: Francesco Di Virgilio,

University of Ferrara, Italy

Robson Coutinho-Silva,

Federal University of Rio de Janeiro,

Brazil

Luiz Eduardo Baggio Savio, Federal University of Rio de Janeiro,

Brazil

*Correspondence:

Miguel Díaz-Hernández

migueldiaz@ucm.es

tThese authors have contributed equally to this work

${ }^{\ddagger}$ Present address:

Laura de Diego-García,

Department of Physiology and Medical Physics, Royal College of Surgeons in Ireland, Dublin, Ireland

Álvaro Sebastián-Serrano,

Centro de Investigación Biomédica en

Red sobre Enfermedades

Neurodegenerativas,

Instituto de Salud Carlos III,

Madrid, Spain

Lisardo Boscá,

Centro de Investigación Biomédica en

Red sobre Enfermedades

Cardiovasculares, Instituto de Salud

Carlos III, Madrid, Spain

Received: 24 January 2019

Accepted: 22 March 2019

Published: 12 April 2019

Citation:

Martínez-Frailes C, Di Lauro C,

Bianchi C, de Diego-García L,

Sebastián-Serrano Á, Boscá $L$ and

Díaz-Hernández M (2019) Amyloid

Peptide Induced Neuroinflammation

Increases the P2X7 Receptor Expression in Microglial Cells, Impacting on Its Functionality. Front. Cell. Neurosci. 13:143. doi: 10.3389/fncel.2019.00143

\section{Amyloid Peptide Induced Neuroinflammation Increases the P2X7 Receptor Expression in Microglial Cells, Impacting on Its Functionality}

\author{
Carlos Martínez-Frailes ${ }^{1,2+}$, Caterina Di Lauro ${ }^{1,2+}$, Carolina Bianchi, ${ }^{1,2}$, \\ Laura de Diego-García ${ }^{1,2 \neq}$, Álvaro Sebastián-Serrano ${ }^{1,2,3 \neq}$, Lisardo Boscá ${ }^{3 \ddagger}$ and \\ Miguel Díaz-Hernández ${ }^{1,2 *}$
}

1 Department of Biochemistry and Molecular Biology, Veterinary School, Complutense University of Madrid, Madrid, Spain, 2 Instituto de Investigación Sanitaria del Hospital Clínico San Carlos, Madrid, Spain, ${ }^{3}$ Instituto de Investigaciones Biomedicas "Alberto Sols", Consejo Superior de Investigaciones Cientificas-Universidad Autónoma de Madrid, Madrid, Spain

Alzheimer disease is a neurodegenerative disease characterized by the presence of senile plaques composed of amyloid- $\beta$ ( $A \beta$ ) peptide, neurofibrillary tangles, neuronal loss and neuroinflammation. Previous works have revealed that extracellular ATP, through its selective receptor P2X7 (P2X7R), is essential to neuroinflammation and neurotoxicity induced by $A \beta$. P2X7R is upregulated on microglial cells around the senile plaques. This upregulation progressively rises with age and is parallel with an accumulation of senile plaques and also correlates with the synaptic toxicity detected both in animal models reproducing $A D$ and human patients of $A D$. Furthermore, the late onset of the first $A D$ associated symptoms suggests that aging associated-changes may be relevant to the disease progression. Thus, microglia motility and its capacity to respond to exogenous ATP stimulus decrease with aging. To evaluate whether the P2X7R age related-changes on microglia cells may be relevant to the AD progression, we generated a new transgenic mouse model crossing an A $\beta$ peptide mouse model, J20 mice and the P2X7R reporter mice ${ }^{\text {P2X7R }}$ EGFP. Our results indicate that neuroinflammation induced by $A \beta$ peptide causes changes in the P2X7R distribution pattern, increasing it s expression in microglial cells at advanced and late stages, when microgliosis occurs, but not in the early stages, in the absence of microgliosis. In addition, we found that P2X7R activation promotes microglial cells migration to senile plaques but decreases their phagocytic capacity. Moreover, we found a significant reduction of P2X7R transcription on neuronal cells at the early and advanced stages, but not at the late stages. Since previous studies have reported that either pharmacological inhibition or selective downregulation of P2X7R significantly improve behavioral alterations and reduce the incidence and size of senile plaques in the early and advanced stages of $A D$, the results presented here provide new evidence, indicating that this therapeutic approach could be also efficient in the late stages of the disease.

Keywords: senile plaques, neuroinflammation, LPS, BzATP, ATP, Alzheimer disease, phagocytosis, migration 


\section{INTRODUCTION}

Alzheimer disease $(\mathrm{AD})$ is a neurodegenerative disease for which, currently, there is no effective treatment available. At a neuropathological level, the disease is characterized by the presence of a profound cortical atrophy associated with a generalized neuroinflammation state (Gahtan and Overmier, 1999), synaptic contacts loss, neuronal depletion and two histopathological hallmarks, the extracellular amyloid plaques and the intracellular neurofibrillary tangles (Selkoe, 2001; Avila, 2006). Neurofibrillary tangles are assembled by hyperphosphorylated tau protein whereas the amyloid plaques are primarily composed of $A \beta$-amyloid $(A \beta)$ peptide, which is derived from sequential proteolysis of the APP by $\beta$ - and $\gamma$-secretases (Selkoe, 2001). In $2-5 \%$ of AD cases have been found mutations both in APP protein and enzymes related in its processing (PS1 and PS2). These cases are denominated as Familiar Alzheimer disease or FAD (Price and Sisodia, 1998; Ling et al., 2003). The development of different transgenic animal models that mimic the FAD symptoms have allowed the confirmation that $\mathrm{A} \beta$ peptide is one of the toxic species involved in AD (Hsiao et al., 1996; Mucke et al., 2000; Radde et al., 2006).

Over recent years, several pieces of evidence, provided by different groups, indicate that extracellular ATP plays a crucial role in APP-induced toxicity, primarily through the activation of its selective ionotropic receptor P2X7 (P2X7R). It was found that ATP regulates APP processing via $\mathrm{P} 2 \mathrm{X} 7 \mathrm{R}$ (Delarasse et al., 2011; Leon-Otegui et al., 2011; DiazHernandez et al., 2012). A negative association between the $\mathrm{P} 2 \mathrm{X} 7 \mathrm{R}$ 489C $>\mathrm{T}$ polymorphism and $\mathrm{AD}$ has also been established (Sanz et al., 2014). Upregulation of P2X7R was found in $\mathrm{AD}$ patients (McLarnon et al., 2006; Sanz et al., 2009; Martin et al., 2018), especially in microglial cells around the senile plaques (Parvathenani et al., 2003). Interestingly, P2X7R upregulation was seen to progressively rise with age and parallels the accumulation of senile plaques (Lee et al., 2011), and correlates with the synaptic toxicity associated to $\mathrm{AD}$ (Lee et al., 2011). In agreement with these findings, i.c. of $\mathrm{A} \beta$ peptides induced gliosis, hippocampal neurons loss and an increase of hippocampal P2X7R expression (Ryu and Mclarnon, 2008), and the pharmacological P2X7R-blockage reverted the memory impairment associated (Chen et al., 2014). The fact that i.c. of $A \beta$ to $P 2 X 7 R$ deficient mice did not cause the above alterations mentioned, suggests that P2X7R is essential

\footnotetext{
Abbreviations: $\mathrm{A} \beta$ peptide, amyloid- $\beta$; AD, Alzheimer disease; APP, amyloid precursor protein; ATP, Adenosine $5^{\prime}$-triphosphate; BSA, bovine serum albumin; BzATP, 2',3'-O-(4-benzoyl)-benzoyl ATP; CNS, central nervous system; CytoD, Cytochalasin D; DAPI, 4',6-Diamidine-2'-phenylindole dihydrochloride; DMEM, Dulbecco's Modified Eagle Medium; DMSO, dimethyl sulfoxide; EGFP, enhance green fluorescent protein; FAD, Familiar Alzheimer disease; FBS, fetal bovine serum; GLDG, granular layer of the dentate gyrus; HEPES, 4-(2-hydroxyethyl)1-piperazineethanesulfonic acid; HRP, horseradish peroxidase; i.c., intracranial administration; i.p., intraperitoneally; J20 mice, mouse model of Familiar

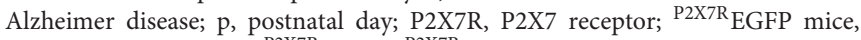
P2X7R reporter mice ${ }^{\mathrm{P} 2 X 7 \mathrm{R}}$ EGFP; ${ }^{\mathrm{P} 2 \mathrm{X} 7 \mathrm{R}} \mathrm{EGFP} / \mathrm{J} 20$, mice generated crossing

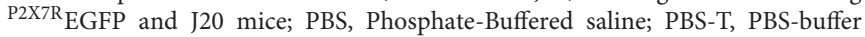
containing $0.1 \%(\mathrm{v} / \mathrm{v})$ Tween-20; PFA, paraformaldehyde; PS1 and PS2, presenilin-1 and -2; s.e.m., mean \pm standard error of the mean; SDS-PAGE, Sodium dodecyl sulfate-polyacrylamide gel electrophoresis; WT, wild-type mice.
}

for the microglial activation induced by $A \beta$ peptide (Sanz et al., 2009). Furthermore, it also reported that its selective downregulation promotes microglial phagocytosis of $\mathrm{A} \beta$ peptide (Ni et al., 2013). Nevertheless, the late onset of the first ADassociated symptoms suggests that aging associated-changes may be relevant to the disease progression (Mosher and WyssCoray, 2014). In accordance with this hypothesis, age inducedchanges on microglial morphology are exacerbated in $\mathrm{AD}$ patients (Serrano-Pozo et al., 2013). Microglia motility and its capacity to respond to exogenous ATP stimulus decrease with aging (Koenigsknecht-Talboo et al., 2008; Damani et al., 2011). It has consequently been seen that microglial cells are removing $A \beta$ in early stages more efficiently than in later stages of AD (Solito and Sastre, 2012). All these data suggest that $\mathrm{P} 2 \mathrm{X} 7 \mathrm{R}$ age related-changes on microglia cells are relevant to the AD progression.

In previous studies, we found that in vivo pharmacological P2X7R blockage reduced the number and size of senile plaques downregulating the amyloidogenic processing and promoting the non- amyloidogenic processing of APP in young J20 mice, a FAD mouse model (Diaz-Hernandez et al., 2012). However, J20 mice treated with P2X7R antagonist did not show, either a decreased microglial recruitment toward senile plaques or a significant increase in microglial population, at least, at the tested-age (DiazHernandez et al., 2012). Taking into account the repercussion that the microglia aging appears to have on $\mathrm{AD}$ progression, in the current study, we decided to analyze whether P2X7Rregulated microglial functions, such as microglial activation, phagocytosis or migration are altered over the $\mathrm{AD}$ progression. To address this question, we generated a new transgenic mouse by crossing the AD mouse model, J20 mice, and the P2X7R reporter mice ${ }^{\text {P2X7R }}$ EGFP.

\section{MATERIALS AND METHODS}

\section{Animals}

All animal procedures were carried out at the Universidad Complutense of Madrid, in compliance with National and European regulations (RD1201/2005; 86/609/CEE) following the guidelines of the International Council for the Laboratory Animal Science. The protocol was approved by the Committee of Animal Experiments of the Complutense University of Madrid and the Environmental Counseling of the Comunidad de Madrid, Spain. All animals were housed with food and water available ad libitum and maintained in a temperature-controlled environment on a 12/12 h light/dark cycle with light onset at 08:00 A.M. All surgery was performed under isoflurane anesthesia, and all efforts were made to minimize suffering.

${ }^{\text {P2X7R EGFP reporter mice (Tg [P2rx7-EGFP] }}$ FY174Gsat/Mmcd, stock 011959-UCD) expressing EGFP immediately downstream of P2X7R promoter (SebastianSerrano et al., 2016). J20 hAPP transgenic mouse line express a mutant form of the human amyloid protein precursor bearing both the Swedish (K670N/M671L) and the Indiana (V717F) mutations (APPSwInd), labeled as strain B6.Cg-Tg (PDGFB-APPSwInd) 20Lms/2J. This mouse strain develops the 
characteristic amyloid peptide deposits by $6-8$ months of age

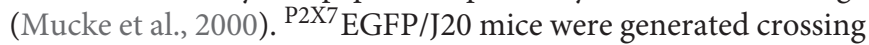
heterozygous ${ }^{\mathrm{P} 2 \mathrm{X} 7}$ EGFP mice by heterozygous J20 mice.

\section{PCR Genotyping}

Genomic DNA was obtained from tail biopsies using Wizard ${ }^{\circledR}$ SV Genomic DNA Purification System (Promega, Madison, WI, United States) according to the manufacturer's protocol.

Simple PCR reactions were carried out using DNA Amplitools Master Mix (Biotools, Madrid, Spain), specific primers (400 nM each) and $5 \mu \mathrm{L}$ of genomic DNA in a final volume of $25 \mu \mathrm{L}$. Animals were genotyped using specific primers for

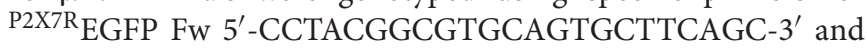
Rv 5'-CGGCGAGCTGCACGCTGCGTCCTC-3'; primers for J20 Fw $5^{\prime}$-GGTGAGTTTGTAAGTGATGCC-3' and Rv $5^{\prime}$ TCTTCTTCTTCCACCTCAGC- $3^{\prime}$. PCR was carried out over 40 cycles of $94^{\circ} \mathrm{C}$ for $30 \mathrm{~s}, 60^{\circ} \mathrm{C}$ for $45 \mathrm{~s}$, and $72^{\circ} \mathrm{C}$ for $45 \mathrm{~s}$ for EGFP primers or over 40 cycles of $94^{\circ} \mathrm{C}$ for $30 \mathrm{~s}, 60^{\circ} \mathrm{C}$ for $45 \mathrm{~s}$, and $72^{\circ} \mathrm{C}$ for $45 \mathrm{~s}$ for $\mathrm{J} 20$ primers.

PCR amplification products were electrophoresed on a $1.5 \%$ $(w / v)$ agarose gel and stained with SYBR ${ }^{\circledR}$ Safe DNA Gel Stain (Life Technologies, Carlsbad, CA, United States). PCR bands were visualized by gel imaging system Gel Logic 200 Imaging System (Kodak, Rochester, NY, United States).

\section{Human Samples}

The Netherlands Brain Bank provided the human brain tissues, which supplies postmortem specimens from clinically well documented and neuropathologically confirmed $\mathrm{AD}$ patients and non-diseased donors (NBB, Netherlands Institute for Neuroscience, Amsterdam). The NBB works following all national laws and regulations. Frozen samples used were obtained from three different regions of the temporal lobe (inferior, medial, and superior) from four patients with the clinical diagnosis of $\mathrm{AD}$ (three women aged 73, 83, and 85 years old and one man aged 85 years) and four non-demented controls (three women aged 70,72 , and 85 years old and one man aged 73 years) following the protocols of nervous tissue donation approved by the local Ethical Committees of the Netherlands Brain Bank. The postmortem delay in tissue processing was between 4 and $5 \mathrm{~h}$ in both groups.

\section{Microglial Cell Culture}

Primary microglial cultures were prepared from the hippocampus of WT at postnatal (p) 4-5 days as previously described (de Diego Garcia et al., 2018). Mixed glial culture containing both astrocytes and microglial was maintained in a $37^{\circ} \mathrm{C}$ incubator with a humidified atmosphere of $5 \%$ $\mathrm{CO}_{2}$ for 14 days in $75 \mathrm{~cm}^{2}$ flasks containing DMEM medium supplemented with $10 \%$ fetal calf serum (Gibco) $2 \mathrm{mM}$ glutamine, $100 \mu / \mathrm{ml}$ penicillin, $100 \mu \mathrm{g} / \mathrm{ml}$ streptomycin, $50 \mu \mathrm{g} / \mathrm{ml} \mathrm{kanamycin}$, and $0.25 \mu \mathrm{g} / \mathrm{ml}$ Amphotericin B (all from Sigma-Aldrich). The medium was replaced every 3 days. Microglial cells were de-attached by shaking the culture flasks at $250 \mathrm{rpm}$ for $2 \mathrm{~h}$ at $37^{\circ} \mathrm{C}$ in an orbital shaker. Microglia cells were plated at $5 \times 10^{5}$ cells/well in six-well plates and cultured in supplemented DMEM media (Thermo Fisher).

\section{Chemical and Antibodies}

LPS, ATP, BzATP (catalog number B6396), and the antibody anti- $\alpha$-tubulin (catalog number T6199) were purchased from Sigma-Aldrich (Madrid, Spain). Anti-NeuN antibody (catalog number MAB377) were obtained from Merck Millipore (Tullagreen, Ireland). A438079 (catalog number 2972/10) was obtained from Tocris BioScience (Bristol, United Kingdom). Monoclonal anti $A \beta \quad 4-10$ residues clone WO2 (catalog number MABN10) was purchased from Merck Chemicals (Madrid, Spain). The commercial antibody for P2X7R (catalog number APR-004) was purchased from Alomone Labs (Jerusalem, Israel). Antibodies against enhanced green fluorescent protein (EGFP) were obtained from Thermo Fisher (catalog number A11122) and AVESLab (catalog number GFP-1020) (Tigard, OR, United States). Red Fluorescent $2 \mu \mathrm{m}$ diameter microspheres (catalog number F8826) (Life technologies). Antibody against Iba-1 (catalog number 019-19741) was provided from Wako (Richmond, VA, United States). CytoD (catalog number sc-201442) was provided by Santa Cruz (Dallas, TX, United States). Selective P2X7R antagonist GSK 1482160A was provided by GlaxoSmithKline (Madrid, Spain)

\section{Phagocytosis Assays}

In vitro; Phagocytosis assays were performed $24 \mathrm{~h}$ after microglial cell seeding on coverslips of $35-\mathrm{mm}$ of diameter. Pharmacological treatments were applied $20 \mathrm{~min}$ before adding the fluorescencent microspheres. Red Fluorescent $2 \mu \mathrm{m}$ diameter microspheres (Life Technologies) at 0,002\% in DMEM medium were added to microglial cells, and afterward, cells were put back in the incubator and left to rest for $2 \mathrm{~h}$. Then, the medium was removed, and cells were washed thoroughly with PBS three times and fixed in PFA $4 \%$.

Microglial cells were stained with a rabbit polyclonal anti-Iba1 $(1 / 200)$ obtained from Wako and revealed with goat anti-rabbit IgG labeled with Alexa 488 (1/400) obtained from Molecular Probes. For each coverslip, 4 random pictures were taken, using the TCS SPE confocal microscope (Leica Microsystems, Wetzlar, Germany). Images were analyzed using ImageJ software (US National Institutes of Health, Bethesda, MD, United States). The number of fluorescent beads inside each cell was counted, and the average number of phagocyted microspheres per microglial cell was calculated for each experiment and treatment. Experiments were repeated at least 3 times for each condition.

In vivo; 6-month-old ${ }^{\text {P2X7R }}$ EGFP mice $(n=6)$ were anesthetized with isoflurane (1-chloro-2, 2, 2-trifuoroethyldifluormethylether) (Isovet ${ }^{\circledR}$, BRAUN, Rubi, Barcelona, Spain) diluted in $50 \% \mathrm{O}_{2}$. The scalp was incised along the midline, and one hole was made at the appropriate stereotaxic coordinates from Bregma (mediolateral, $1 \mathrm{~mm}$; anteroposterior, $2 \mathrm{~mm}$; dorsoventral, $1.8 \mathrm{~mm}$ ). $1 \mu \mathrm{L}$ of $0.02 \%$ red Fluorescent $2 \mu \mathrm{m}$ microspheres in PBS was intracranial administrated (i.c.) at a rate of $\approx 1 \mu \mathrm{L} / \mathrm{min}$.

In some cases, the selective P2X7R antagonist GSK 1482160A (from GlaxoSmithKline, Madrid, Spain) was i.p. administrated at $100 \mathrm{mg} / \mathrm{Kg}$ dosage every $24 \mathrm{~h}$ for 1 week. GSK $1482160 \mathrm{~A}$ was 
diluted in vehicle solution composed of $20 \%$ hydroxypropyl$\beta$-cyclodextrin plus $0.2 \%$ DMSO in sterile PBS. Control littermates were treated with vehicle solution using the same relationship (volume per body weight).

\section{Migration Assay}

The migration assays were performed placing $1.5 \times 10^{5}$ hippocampal microglia cells contained in $200 \mu \mathrm{L}$ of serum free in the upper chamber of the 24-well format, $8.0 \mu \mathrm{m}$ pore size transwell inserts (Costar, New York, NY, United States), and $600 \mu \mathrm{L}$ of the same medium containing $10 \%$ of FBS in the lower chamber. In some cases, cells were pre-treated with $1 \mu \mathrm{M}$ GSK 1482160A before stimulating them with $1 \mathrm{mM}$ ATP or $300 \mu \mathrm{M}$ BzATP for $24 \mathrm{~h}$ at $37^{\circ} \mathrm{C}$ in $5 \%$ of $\mathrm{CO}_{2}$. The inserts were subsequently removed rinsing twice with PBS and fixed in 4\% PFA for $10 \mathrm{~min}$, followed by staining with DAPI for $10 \mathrm{~min}$. The cells on the upper side of the filter were removed with cotton-tipped swabs. The microglial migration was quantified by counting the number of cells that migrated through the membrane to the other side. The images were selected from 20 random fields for each treatment with microscopy at 50x magnification, and the number of migrating cells was quantified. Each experiment was repeated at least three times.

\section{LPS Treatment}

${ }^{\mathrm{P} 2 X 7 \mathrm{R}}$ EGFP mice weighing at the indicated ages were i.p. treated with either sterile PBS or LPS ( $5 \mathrm{mg} / \mathrm{Kg}$, Escherichia coli, serotype 055 : B5) ( $n=5$ per age and treatment). Mice were sacrificed $24 \mathrm{~h}$ (acute) or 7 days (chronic) after injection.

\section{Immunofluorescence Studies}

For confocal microscopy, animals were transcardially perfused with $4 \% \mathrm{PFA}$ in Sorensen's buffer for $10 \mathrm{~min}$, post-fixed, and brains were cryoprotected in sucrose before sectioning. Brain slices were washed in PBS and treated with blocking solution containing $5 \%$ FBS, $1 \%$ BSA, and $0.2 \%$ TritonX 100 in PBS buffer. After that, samples were incubated with primary antibodies diluted in blocking solution. After washed them, sections were incubated with fluorescent-tagged secondary antibodies to be counterstained with DAPI (Thermo Fisher) and mounted in FluorSave (Merck Millipore) later. The following primary antibodies were used at the indicated dilutions: mouse anti-APP clone (WO2) 1:200, rabbit antiGFP 1:400, chicken anti-EGFP 1:400, rabbit anti-P2X7R 1:200, rabbit anti-Iba-1 1:200. Donkey anti-rabbit, anti-mouse or antichicken secondary antibodies, conjugated with Alexa 488, 594 or 647 (Life Technologies, Madrid, Spain) were used at 1:400. Confocal images were acquired with a TCS SPE. Confocal images stacks were acquired with a TCS SPE microscope from Leica Microsystems equipped with a Plan Fluor 10X dry objective lens $\mathrm{NA}=0.30,40 \mathrm{X}$ Apochromat $\mathrm{NA}=1.15$ oil objective lens and 63X Apochromat NA $=1.3$ oil objective lens (Leica Microsystems $\mathrm{GmbH}$ ) at room temperature. The images stacks are composite by a sequence of at least 20 pictures acquired every $0.5 \mu \mathrm{m}$ on the $Z$-axis. For the detection of DAPI, $405 \mathrm{~nm}$ laser line was used. For Alexa Fluor 594, the $561 \mathrm{~nm}$ laser line was used. For Alexa Fluor 488, the
$488 \mathrm{~nm}$ laser line was used. For Alexa 647, the $645 \mathrm{~nm}$ laser line was used. Images were acquired using the Leica software LAS AF v2.2.1 software (Leica Microsystems GmbH) and the $\mathrm{Z}$ projection of images stacks was made using Image J $1.47 \mathrm{~d}(\mathrm{NIH})$. In some cases, it also shows orthogonal views corresponding to specific locations (indicated by dashed lines) of images stack. Green cells in the hippocampus were considered those cells positively marked with antibodies against GFP with an identifiable cellular morphology and whose nucleus was positively stained with DAPI.

\section{Quantification of GFP Positive Microglial and Neuron Cells and Distances Measurement}

For each case (at least 4 mice per phenotype, age and treatment) 4 series (16 sections, $90 \mu \mathrm{m}$ apart, approximately spanning from Bregma $-0.95 \mathrm{~mm}$ to $-3.78 \mathrm{~mm}$ according to Paxinos and Franklin (2001) of sections (30 $\mu \mathrm{m}$ thick) were selected to be immunostained with antibodies anti-GFP, anti-Iba-1, anti-P2X7R or anti-APP (clone WO2) respectively. In some cases, hippocampal slices were stained with more than one antibody.

The number of cells corresponding to each cell type was counted, identified by specific antibodies (neurons using NeuN antibody and microglial cells with Iba-1 antibody). The counting was performed using blind-coded on grayscale 8-byte images from whole-hippocampal area acquired at low magnification. The background signal was determined by visual analysis, obtaining a cut-off value of 150 on a $0-255$ scale with $0=$ white and 255 = black using the free software ImageJ 1.45h (US National Institutes of Health, Bethesda, MD, United States).

Distances of GFP positive or P2X7R positive cells to the senile plate were measured from the core of the cellular body, to the border of the nearest senile plate bigger than $30 \mathrm{~nm}$ in its longer axis.

\section{Western Blotting}

Hippocampal samples from WT, J20, ${ }^{\mathrm{P} 2 \mathrm{X} 7 \mathrm{R}} \mathrm{EGFP}$ or ${ }_{\mathrm{P} 2 \mathrm{X} 7 \mathrm{R}} \mathrm{EGFP} / \mathrm{J} 20$ mice and Human samples were treated with lysis buffer containing $20 \mathrm{mM}$ HEPES, $100 \mathrm{mM} \mathrm{NaCl}$, $50 \mathrm{mM} \mathrm{NaF}, 5 \mathrm{mM}$ EDTA, $5 \mathrm{mM} \mathrm{Na}_{3} \mathrm{VO}_{4}$ (all salts from SigmaAldrich), 1\% Triton X-100, okadaic acid and CompleteTM Protease Inhibitor Cocktail Tablets, pH 7.4 (Roche Diagnostics $\mathrm{GmbH})$. Protein concentration was determined, and then, samples were boiled in a gel-loading buffer and separated by SDS-PAGE. Proteins were transferred to nitrocellulose membranes and probed with the following primary antibodies: rabbit anti- P2X7R (1:1000) antibody or mouse anti- $\alpha$-tubulin $(1: 10000)$ antibody. Blots were then washed in PBS-T and incubated with goat anti-rabbit or goat anti-mouse IgGs coupled with HRP (Amersham GE Healthcare), used at 1:1000 and 1:5000, respectively. Protein bands were visualized by chemiluminescence (Pierce Biotechnology, Rockford, IL, United States) using ImageQuant LAS500 (GE Healthcare Life Sciences) and analyzed using ImageJ software (v1, 47d, NIH, Bethesda, MD, United States). 


\section{Statistical Analysis}

Results were analyzed by unpaired $t$-test or ANOVA test followed by Bonferroni's or Sidak's multiple comparisons tests using GRAPH PAD PRISM 6 (Graph Pad Software Inc., San Diego, CA, United States) and expressed as the s.e.m. Differences were considered to be significant at $p<0.05$.

\section{RESULTS}

\section{In a Familiar Alzheimer Disease Mouse Model (FAD), Microglial Cells Begin to Express P2X7R at Adult Stages, Once Microgliosis Takes Place}

To elucidate if $A \beta$ peptide conditions the P2X7R expression on microglial cells along the $\mathrm{AD}$ progression, we generated a new transgenic mouse model by crossbreeding the amyloid mice model of the $\mathrm{AD}, \mathrm{J} 20$ mice with the ${ }^{\mathrm{P} 2 \mathrm{X} 7 \mathrm{R}} \mathrm{EGFP}$ mice that express EGFP under the control of the P2X7R promoter. ${ }^{\mathrm{P} 2 \mathrm{X} 7 \mathrm{R}} \mathrm{EGFP} / \mathrm{J} 20$ and their corresponding control littermates ${ }^{P 2 X 7 R}$ EGFP mice were sacrificed to analyze their hippocampus by immunofluorescence techniques at the following ages; 4-6 months-old (early stage), 10-12 months-old (advanced stage), and 16-20 months-old (late stage). Results showed that EGFP positive cells were mainly found on the GLDG on both genotypes and at all ages tested. In addition, disseminated EGFPpositive cells throughout the whole hippocampus were also found (Figure 1A). Double immunofluorescence studies using specific neuronal marker NeuN or glial markers GFAP and Iba-1 for astroglial cells and microglial cells respectively revealed that EGFP positive cells on GLDG were neurons while disseminated extra granular EGFP-positive green cells were microglial cells (Supplementary Figure 1). Curiously, in the early and advanced stages, the number of EGFP-positive neurons in GLDG was lower in ${ }^{\text {P2X7R }}$ EGFP/J20 than observed in ${ }^{\text {P2X7R }}$ EGFP mice (7.9 \pm 0.4 $10^{4}$ vs. $5.4 \pm 0.510^{4}$ in the early stages and $8.3 \pm 0.410^{4}$ vs. $6.3 \pm 0.610^{4}$ in the advanced stages, Figures 1 A,D). However, no change on EGFP-positive neurons in GLDG was found between ${ }^{\text {P2X7R }}$ EGFP/J20 and ${ }^{\text {P2X7R }}$ EGFP mice at late stages $\left(8.7 \pm 0.310^{4}\right.$ vs. $8.2 \pm 0.510^{4}$ in the late stages, Figures $\mathbf{1 A}, \mathbf{D}$ ). Otherwise, P2X7R EGFP/J20 mice presented a higher number of disseminated EGFP-positive microglial cells than those observed in their corresponding control littermates ${ }^{\text {P2X7R }}$ EGFP mice both in the advanced and late stages $(1.5 \pm 0.3$ vs. $6.4 \pm 1.0$ in the advanced stages and $4.3 \pm 0.6$ vs. $7.7 \pm 0.6$ in late stages, Figures $\mathbf{1 A}, \mathbf{C}$ ). Non-differences in the number of EGFP-positive microglial cells were found between ${ }^{\mathrm{P} 2 \mathrm{X} 7 \mathrm{R}} \mathrm{EGFP} / \mathrm{J} 20$ and ${ }^{\mathrm{P} 2 \mathrm{X} 7 \mathrm{R}}$ EGFP mice in the early stages $(0.6 \pm 0.2$ vs. $1.6 \pm 0.5$, Figures $\mathbf{1 A , C})$. It is worth highlighting that while ${ }^{\mathrm{P} 2 \mathrm{X} 7 \mathrm{R}} \mathrm{EGFP} / \mathrm{J} 20$ and ${ }^{\mathrm{P} 2 \mathrm{X} 7 \mathrm{R}} \mathrm{EGFP}$ mice showed, in the early stages, a similar number of hippocampal microglial cells, in the advanced and late stages, ${ }^{\mathrm{P} 2 \mathrm{X} 7 \mathrm{R}} \mathrm{EGFP} / \mathrm{J} 20$ mice presented a significant increase of microglial cells compared with those detected in their corresponding littermates ${ }^{\text {P2X7R }}$ EGFP mice (Figures 1A,B). These data indicate that in the FAD early stages, when a microgliosis had not yet taken place but the senile plaques start to be detected (Figure 1A), negative modulation of P2X7R transcription occurs in neurons, but did not affect microglial cells. Conversely, in FAD advanced stages, once a significant microgliosis begins to be detected and the number of senile plates increase (Figures 1A,B), a rise of P2X7R transcription occurs in microglial cells, but the reduction of P2X7R transcription is maintained in neurons. Finally, in the late stages of the $\mathrm{FAD}$, when microgliosis remains over time, the increased of P2X7R transcription remains in microglial cells, but the neuronal reduction of $\mathrm{P} 2 \mathrm{X} 7 \mathrm{R}$ transcription disappears.

In the following step, we decided to check if the changes observed in P2X7R transcription affected the protein expression of this receptor. To this end, we measured P2X7R protein expression levels in hippocampal samples from WT and J20 mice at the same ages as those we had previously analyzed ${ }^{\mathrm{P} 2 X 7 R}$ EGFP/J20 and ${ }^{\mathrm{P} 2 X 7 \mathrm{R}}$ EGFP mice. Results revealed that J20 mice, at the early stages, presented similar P2X7R levels to those observed in their control littermates. However, in their advanced and late stages, J20 mice showed higher P2X7R expression levels than those detected in their corresponding control littermates (209 $\pm 34 \%$ in the advanced stages and $140 \pm 9 \%$ in the late stages, Figures 2A,B). Double immunofluorescence studies using P2X7R and Iba-1 antibodies showed that, similarly to that observed in ${ }^{\mathrm{P} 2 \mathrm{X} 7 \mathrm{R}} \mathrm{EGFP} / \mathrm{J} 20$ mice, J20 mice presented a higher number of P2X7R positive microglial cells than those detected in their corresponding control littermate WT mice both in the advanced and late stages $(4 \pm 1 \%$ vs. $13 \pm 1 \%$ in the advanced stages and $5 \pm 1 \%$ vs. $18 \pm 1 \%$ in the late stages (Figures 2C,D). Interestingly, something similar was observed in ${ }^{\text {P2X7R EGFP }}$ mice, the percentage of positive P2X7R microglial cells was low in WT mice at all ages tested (Figures 1C, 2C). When we analyzed the distribution pattern of P2X7R positive microglial cells, we found them mainly localized inside senile plaques at all ages tested (Figure 2F). However, P2X7R positive microglial cells were not abundant at this location (Figure 2E). It is also worth noting that the J20 mice did not show any significant differences, either in the total number $(12.0 \pm 1.2$ and $15.3 \pm 1.2$ respectively), or in the percentage of EGFP-positive microglial cells $(9 \pm 2 \%$ and $90 \pm 2 \%$ respectively) inside the senile plates between their advanced and late stages (Figures 2E,F).

Similar to what was observed in J20 mice at advanced and late stages, we detected a significantly increased of P2X7R expression in samples from human AD patients (Figures 3E,F). Immunofluorescence studies using human brain samples confirmed that $\mathrm{P} 2 \mathrm{X} 7 \mathrm{R}$ is expressed in microglial cells (Figure 3A), although the number of microglial cells expressing P2X7R was lower than those non-expressing this receptor (Figure 3B). Regarding their distribution pattern, we observed, once again, that positive P2X7R microglial cells were preferentially inside extracellular $\beta$-amyloid deposits (Figures 3C,D). These results confirm that J20 mice mimics the microglial P2X7R location observed in human AD patients.

\section{Neuroinflammation Changes the P2X7R Distribution Pattern}

Once we had observed that, both in FAD mouse models and human $\mathrm{AD}$ patients, the increased P2X7R expression occurred in 

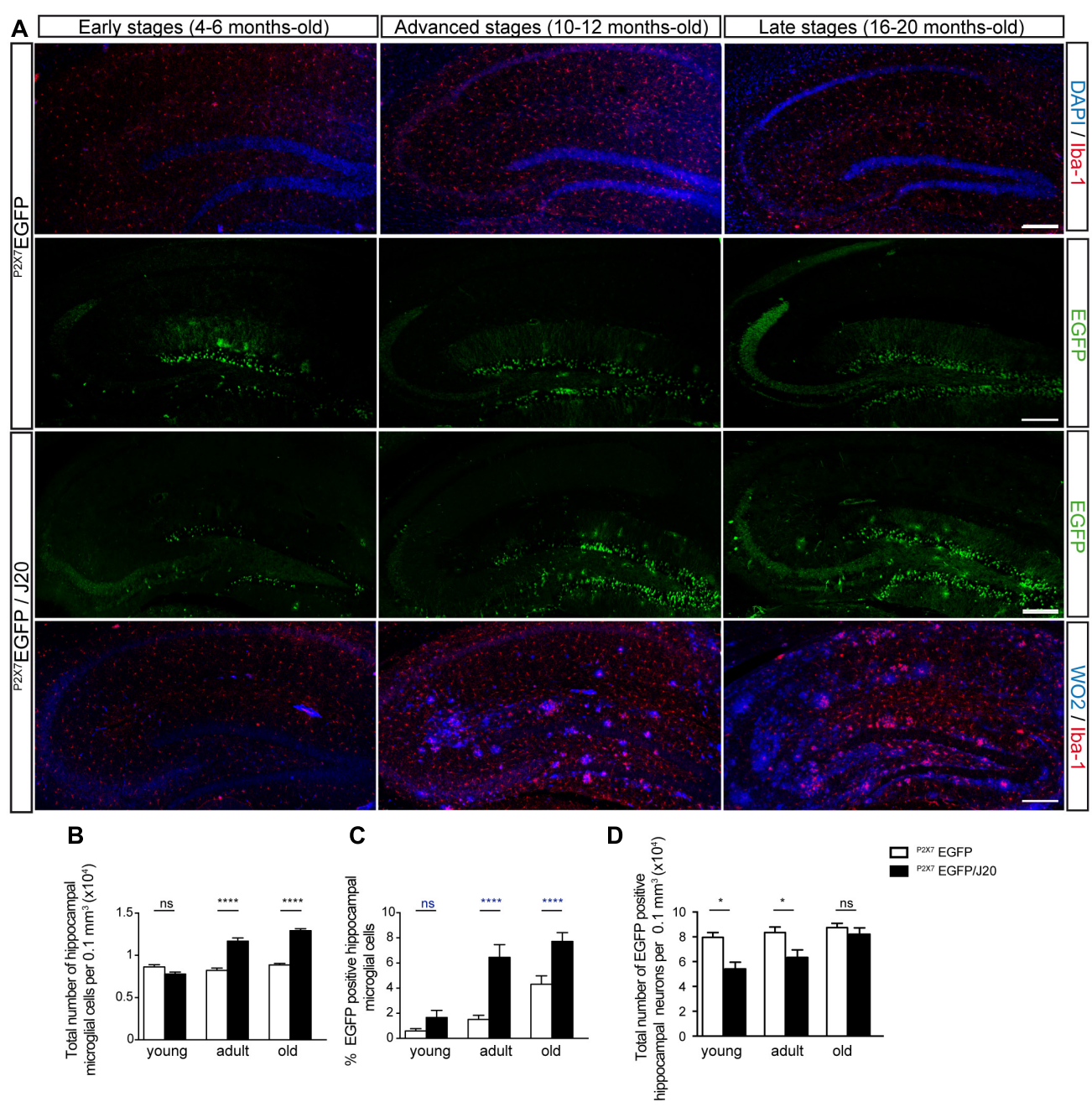

FIGURE 1 | Microgliosis in P2X7REGFP/J20 mice promotes increased expression of the P2X7R reporter protein in microglial cells and reduces it in neurons. (A) Representative images of hippocampal coronal sections from P2X7REGFP and P2X7REGFP/J20 mice at 4-6 months-old (early stage), 10-12 months-old (advanced stage) and 16-20 months-old (late stage). Sections from P2X7REGFP mice stained with nuclear marker DAPI plus microglial marker Iba-1 or antibodies

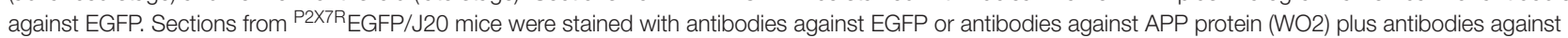
Iba-1. Scale bar: $200 \mu \mathrm{m}$. (B) The total number of microglia cells per $0.1 \mathrm{~mm}^{3}$ of the hippocampal section on P2X7REGFP mice (white bars) and P2X7REGFP/J20 mice (black bars) at each analyzed age. (C) Percentage of hippocampal EGFP positive microglial cells on P2X7REGFP mice (white bars) and P2X7REGFP/J20 mice (black bars) at each indicated age ( $n \geq 5$ mice per genotype and age; sections $\geq 9$ per mouse). (D) Quantification of EGFP positive neurons per 0.1 mm ${ }^{3}$ of the hippocampal section on P2X7REGFP mice (white bars) and P2X7REGFP/J20 mice (black bars) at each analyzed age ( $n \geq 5$ mice per genotype and age; sections $\geq 9$ per mouse). ${ }^{*} p<0.05$ and ${ }^{* * * *} p<0.0001$ using an unpaired $t$-test, ns not statistically significant. Data in bar graphs represent mean \pm s.e.m.

microglial cells, we decided to identify the factors causing it, as well as its consequences on microglial functionality.

As, in studies using J20 mice, we observed that the P2X7R distribution pattern changed when a significant increase in microglial cells took place, initially, we decided to evaluate if the associated neuroinflammation process might be one of the factors involved in it. To assess this hypothesis, we decided to resort to the LPS-induced neuroinflammation model. Additional groups of young, adult and old ${ }^{\mathrm{P} 2 \mathrm{X} 7 \mathrm{R}} \mathrm{EGFP}$ mice were treated i.p. with LPS or vehicle solution for $24 \mathrm{~h}$ or 7 days. Results showed that, although the LPS administration did not modify the P2X7R hippocampal expression levels (Figure 4A), it did, however, induce a similar P2X7R distribution pattern change to the one observed in ${ }^{\mathrm{P} 2 \mathrm{X} 7 \mathrm{R}} \mathrm{EGFP} / \mathrm{J} 20$ mice (Figure 4B). LPStreated ${ }^{P 2 X 7 R}$ EGFP mice presented a significant increase in EGFP-positive microglial cells throughout the hippocampus at all ages tested. This change was independent of the treatment duration (Figures 4B,D). This fact was linked to a significant increase in the total number of hippocampal microglial cells (Figure 4C). Curiously, only 7 days-LPS-treated P2X7REGFP old mice did not show a significant increase of EGFP-positive microglial cells when compared to their respective 7 days-vehicle-treated ${ }^{\text {P2X7R }}$ EGFP old mice (4.6 \pm 0.9 vs. $7.8 \pm 0.7$, Figures $4 \mathbf{4}, \mathbf{D})$. Moreover, we found, once more, in young and adult LPS-treated P2X7REGFP mice, a significant decrease in the EGFP-positive neurons in GLDG 

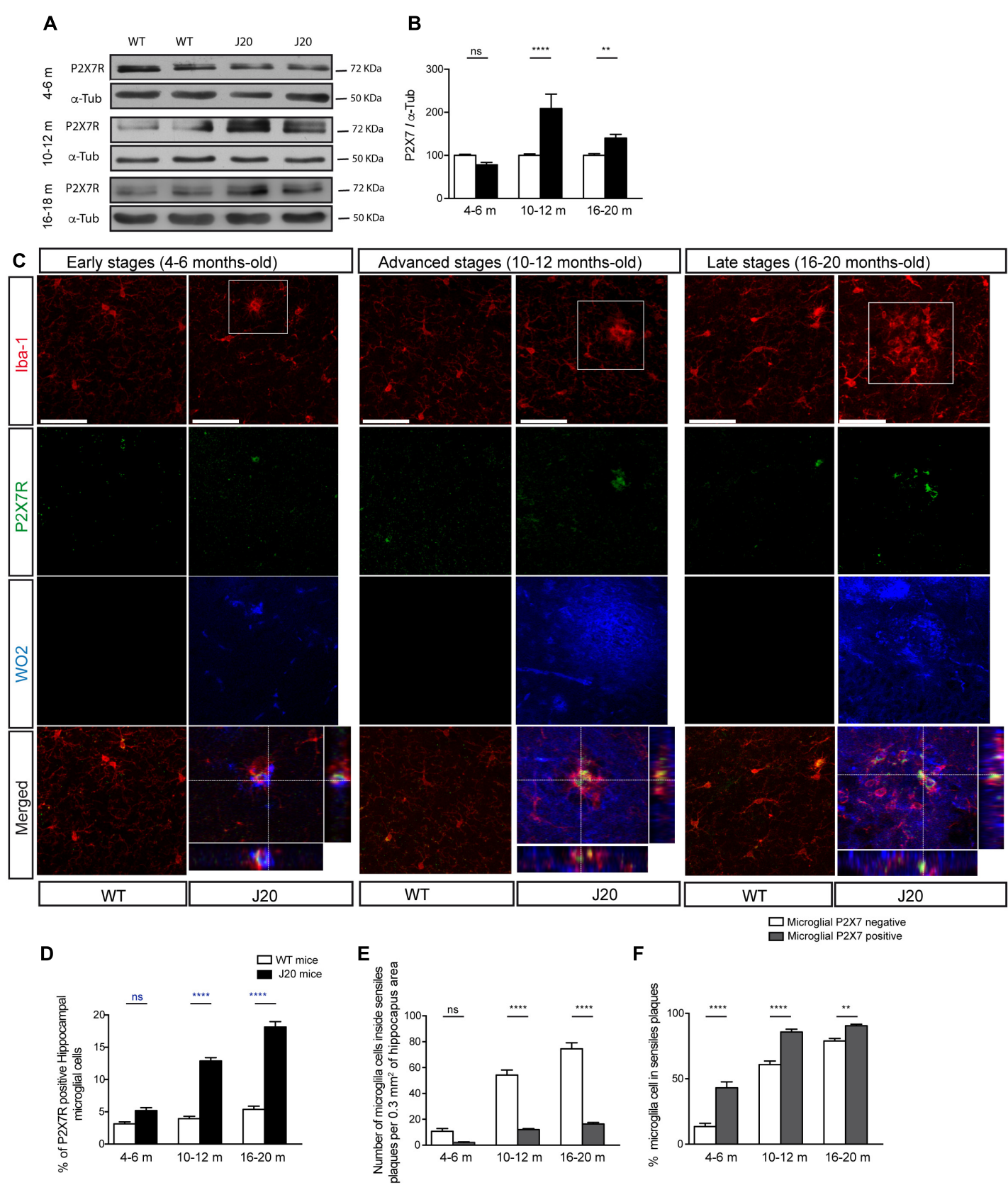

FIGURE 2 | J20 mice increase the P2X7R expression levels in microglial cells at advanced and late stages when they develop a significant microgliosis. (A) Representative images of Western blot using hippocampal samples from J20 at 4-6 months-old (early stage), 10-12 months-old (advanced stage), and 16-20 months-old (late stage) and their corresponding control-littermates (WT) mice stained with antibodies against constitutive P2X7R or $\alpha$-tubulin. (B) Graphs show quantification of the protein expression of P2X7 receptor ( $n \geq 6$ mice per genotype and age). Data were normalized using $\alpha$-tubulin levels. The $100 \%$ value indicates the corresponding P2X7R protein expression detected in WT mice. ${ }^{* *} p<0.01$ and ${ }^{* * * *} p<0.0001$ using unpaired $t$-test. (C) Representative micrographs of hippocampal sections from J20 and WT mice at early, advanced or late stages stained with antibodies against P2X7 receptor (green), microglial marker Iba-1 (red), and APP protein (WO2) (blue). Merged images both the full field and a magnification 1.5x of the area indicated in upper images are shown at the bottom with their corresponding orthogonal views. Dashed lines represent the locations where orthogonal views were obtained. Scale bar: $50 \mu \mathrm{m}$. (D) The graph shows the percentage of positive P2X7R microglial cells in WT (white) or J20 (black) mice per $0.1 \mathrm{~mm}^{3}$ of hippocampal section ( $n \geq 5$ mice per genotype and age; sections $\geq 10$ per mouse). (E) Quantification of the total number of microglial cells expressing (gray) or not P2X7R (white) inside of senile plaques per 0.3 mm ${ }^{3}$ of the hippocampal section. (F) Percentage of hippocampal microglial cells expressing (gray) or not P2X7R (white) inside of senile plaques ( $n \geq 5$ mice per genotype and age; sections $\geq 8$ per mouse). The $100 \%$ value corresponded to the total number of microglial cells expressing or not P2X7R. ${ }^{* *} p<0.01$ and ${ }^{* * * *} p<0.0001$ using an unpaired $t$-test, ns not statistically significant. Data in bar graphs represent mean \pm s.e.m. 

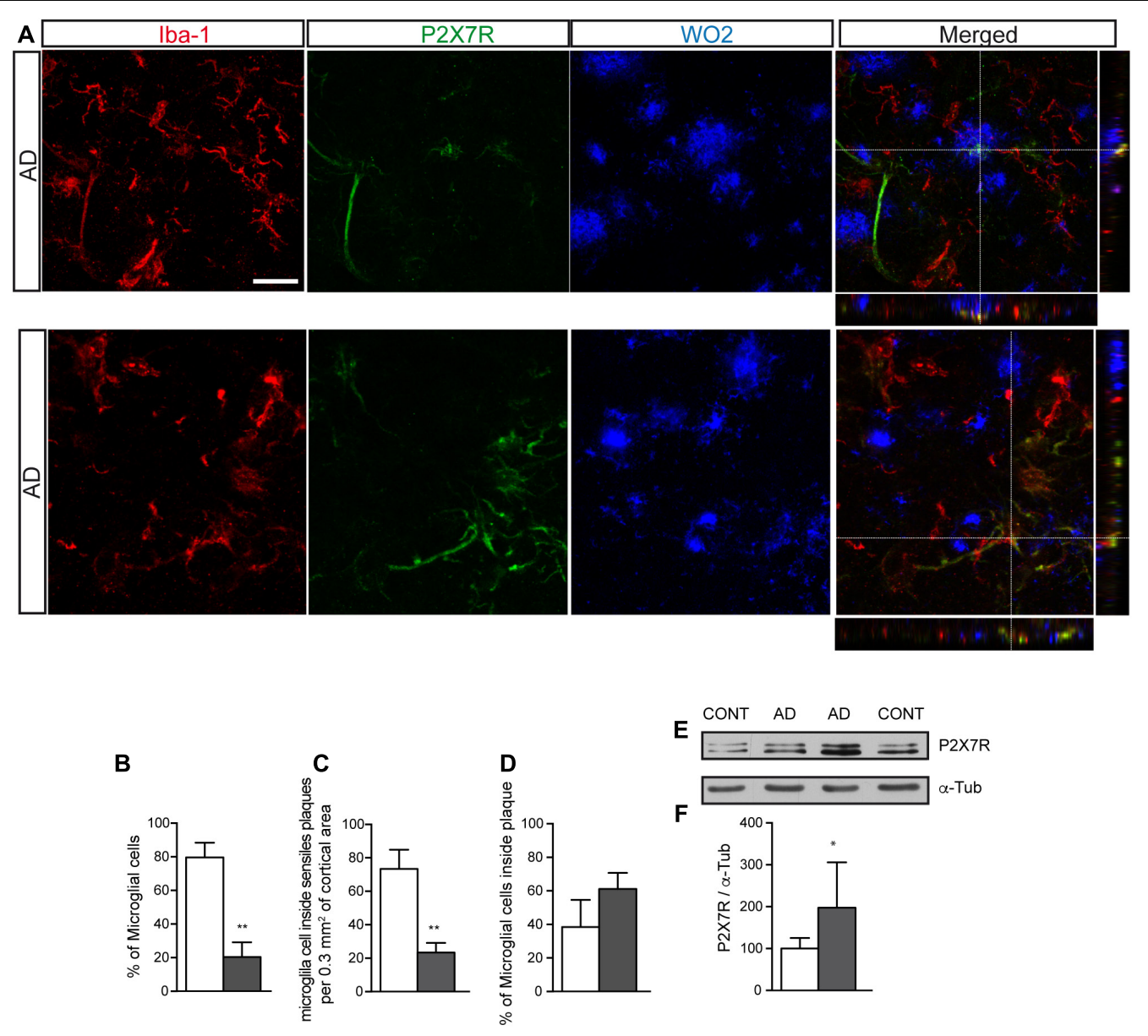

FIGURE 3 | Human AD patients showed a significantly increased P2X7R expression in microglial cells, preferably localized inside of senile plaques.

(A) Representative images of post-mortem cortical sections from AD patients stained with antibodies against P2X7 receptor (green), microglial marker Iba-1 (red) and APP protein (WO2) (blue). Merged images and orthogonal views are also shown. Dashed lines represent the locations where orthogonal views were obtained. Scale bar: $20 \mu \mathrm{m}$. (B) The graph shows the percentage of microglial cells expressing (gray) or not (white) P2X7R in post-mortem cortical sections from human AD patients ( $n=4$; sections $\geq 10$ per case). (C) Quantification of the total number of microglial cells expressing (gray) or not P2X7R (white) inside of senile plaques per 0.3 mm ${ }^{3}$ of the cortical area. (D) Percentage of hippocampal microglial cells expressing (gray) or not P2X7R (white) inside of senile plaques. ( $n=4$; sections $\geq 10$ per case). The $100 \%$ value corresponded to the total number of microglial cells. ${ }^{* *} p<0.01$ using unpaired $t$-test. (E) Representative images of Western blot using post-mortem cortical samples from human AD patients or non-demented controls stained with antibodies against P2X7R or $\alpha$-tubulin. (F) Graphs show a quantification of the protein expression of P2X7 receptor ( $n=4 \mathrm{AD}$ and $n=4$ controls). Data were normalized to the expression levels of $\alpha$-tubulin. The $100 \%$ value indicates the corresponding P2X7R protein levels detected in non-demented controls. ${ }^{*} p<0.05$ using unpaired $t$-test. Data in bar graphs represent mean \pm s.e.m.

$(63.1 \pm 7.2 \%$ and $48.1 \pm 10.5 \%$ for $24 \mathrm{~h}$ or 7 days of LPS-treatment respectively on young mice and $66.4 \pm 9.0 \%$ and $40.5 \pm 12.9 \%$ for $24 \mathrm{~h}$ or 7 days of LPS-treatment respectively on adult mice, Figures 4B,E). However, this reduction was not observed in old LPS-treated ${ }^{\text {P2X7R }}$ EGFP mice independently of the treatment duration (Figures 4B,E). To validate the results obtained with ${ }^{\mathrm{P} 2 \mathrm{X} 7 \mathrm{R}} \mathrm{EGFP}$ reporter protein, we performed a new analysis using anti-P2X7R antibodies. Results revealed that LPS-treatment induced a significant increase in P2X7R-positive microglial cells at all ages tested (Figures 4F,G). It is important to consider that, by using this approach, we found a significant increase in the number of P2X7R-positive microglial cells even in LPS-treated old mice (Figures 4F,G). These data are suggesting that P2X7R distribution pattern change detected in J20 mice may be caused by the associated neuroinflammation developed by mice during the progression of the disease.

\section{P2X7R Regulates the Microglial Cell Recruitment to Senile Plate}

Taking into account that our preliminary data revealed that $\mathrm{P} 2 \mathrm{X} 7 \mathrm{R}$ positive microglial cells were mainly inside senile plates, we wondered if P2X7R favors the migration of microglial cells toward them. To address this point, initially, we decided to evaluate the role of $\mathrm{P} 2 \mathrm{X} 7 \mathrm{R}$ on microglial cell migration, using primary microglial cells cultures isolated from the hippocampus. Results showed that high ATP concentration $(1 \mathrm{mM})$ promotes microglial cells migration (6.9 \pm 3.0 migrated microglial cells stimulated by PBS vs. $228.2 \pm 14.2$ migrated microglial cells 

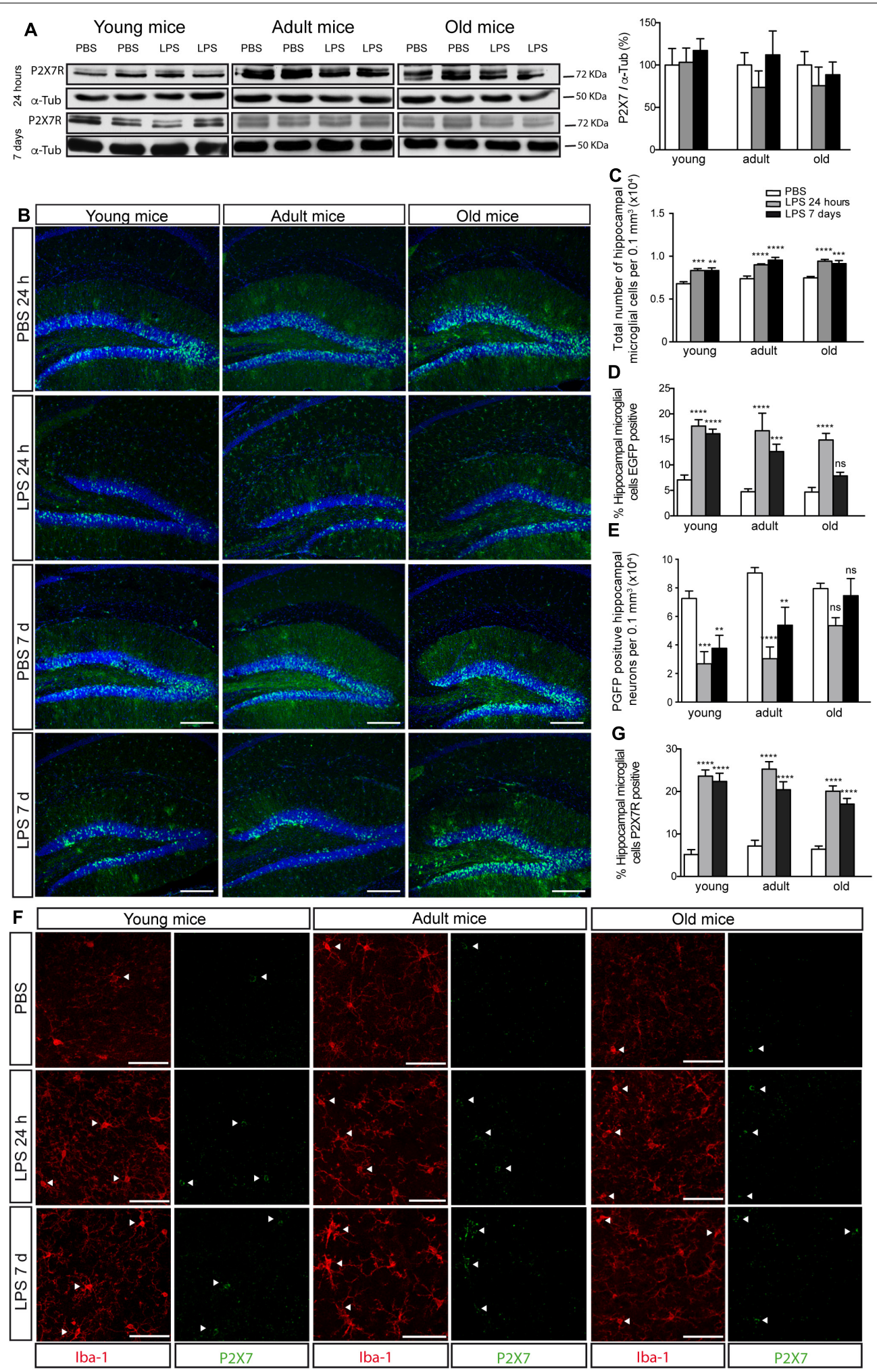

FIGURE 4 | LPS-induced neuroinflammation increases P2X7R in microglial cells and reduces its levels in neurons. (A) Representative images of Western blot using hippocampal samples from young (4-6 months-old), adult (10-12 months old), or old P2X7R EGFP mice (16-20 months-old) intraperitoneally PBS- or LPS-treated for $24 \mathrm{~h}$ or 7 days and stained with antibodies against P2X7R or $\alpha$-tubulin. The graph shows the quantification of P2X7R protein levels ( $n \geq 5$ mice per age and treatment). Data were normalized using $\alpha$-tubulin levels. The 100\% value corresponds to P2X7R protein levels detected in PBS-treated mice. Data in bar graphs 


\section{FIGURE 4 | Continued}

depict mean \pm s.e.m. (B) Representative images of hippocampal coronal sections from young, adult or old P2X7REGFP mice intraperitoneally PBS- or LPS-treated for $24 \mathrm{~h}$ or 7 days and stained with an antibody against EGFP plus nuclear marker DAPI (lower panels). Scale bar: $200 \mu \mathrm{m}$. (C) Quantification of the total number of microglial cells per $0.3 \mathrm{~mm}^{3}$ of the hippocampal section on young, adult or old P2X7REGFP mice intraperitoneally PBS- or LPS-treated for $24 \mathrm{~h}$ or 7 days. (D) Percentage of hippocampal EGFP positive microglial cells on young, adult or old P2X7REGFP mice intraperitoneally PBS- or LPS-treated for 24 h or 7 days. $100 \%$ value corresponded to the total number of microglial cells expressing EGFP in PBS-treated mice. (E) Graphs show the total number of hippocampal neurons expressing EGFP on young, adult or old P2X7REGFP mice intraperitoneally PBS- or LPS-treated for 24 h or 7 days $(n \geq 5$ mice per age and treatment; sections $\geq 8$ per mouse). ${ }^{* *} p<0.01,{ }^{* * *} p<0.001$, and ${ }^{* * *} p<0.0001$ using ANOVA test followed by Bonferroni's tests, ns not statistically significant. Data in bar graphs depict mean \pm s.e.m. (F) Representative micrographs of hippocampal sections from young, adult or old P2X7REGFP mice intraperitoneally PBS- or LPS-treated for 24 h or 7 days and stained with antibodies against P2X7 receptor (green) and microglial marker lba-1 (red). Arrowheads show the microglial cells expressing P2X7R. Scale bar: $50 \mu \mathrm{m}$. (G) The graph shows the percentage of hippocampal microglial cells expressing P2X7R on young, adult or old P2X7REGFP mice intraperitoneally PBSor LPS-treated for $24 \mathrm{~h}$ or 7 days ( $n \geq 5$ mice per age and treatment; sections $\geq 10$ per mouse). ${ }^{* * * *} p<0.0001$ using ANOVA test followed by Bonferroni's tests. Data in bar graphs represent mean \pm s.e.m.

ATP-stimulated, Figure 5A). Since acute stimulation of P2X7R by high ATP concentrations can induce cellular death (MirasPortugal et al., 2017), we decided to stimulate the microglial cells with lower concentrations of ATP $(0.3 \mathrm{mM})$ or with the selective P2X7R agonist BzATP (0.3 mM, Supplementary Figure 2). Both stimulations caused similar results on microglial mobility than that induced high ATP concentration (Supplementary Figure 2). The involvement of P2X7R was confirmed when the selective P2X7R antagonist GSK 1482160A prevented the microglial migration induced by $1 \mathrm{mM}$ ATP $(13.5 \pm 2.6$ migrated microglial cells after being stimulated by ATP in presence GSK 1482160A, Figure 5A) or $300 \mu \mathrm{M}$ BzATP (Supplementary Figure 2). These results point to the fact that $\mathrm{P} 2 \mathrm{X} 7 \mathrm{R}$ is regulating the microglial mobility, and, consequently, ATP may be considered as a chemotaxis signal for microglial cells.

In the following step, to determine whether $\mathrm{P} 2 \mathrm{X} 7 \mathrm{R}$ regulates microglial cells recruitment to senile plates, we decided to analyze ${ }^{\mathrm{P} 2 \mathrm{X} 7 \mathrm{R}} \mathrm{EGFP} / \mathrm{J} 20$ mice. In this study, we measured the number of both EGFP-positive and EGFP-negative microglial cells inside senile plates, as well as the distance between the center of microglial cell to the border of the most closed senile plate. As shown in Figure 5B, in all ages tested we observed higher percentages of EGFP-positive than EGFPnegative microglial inside the senile plates, although only in the advanced and late stages this increase was significant (37.1 $\pm 11.8 \%$ vs. $15.2 \pm 3.5 \%$ respectively in young mice, $66.1 \pm 7.6 \%$ vs. $31.1 \pm 0.8 \%$ respectively in adult mice and $71.2 \pm 1.1 \%$ vs. $38.7 \pm 4.5 \%$ respectively in old mice, Figure 5B). Furthermore, in the early stages, we detected a higher percentage of EGFP-positive microglial cells at the most closed environment of senile plates than EGFPnegative ones $(55.0 \pm 2.8 \%$ vs. $43.8 \pm 2.2 \%$ respectively, Figure 5B). On the other hand, we found a lower percentage of EGFP-positive microglial cells than EGFP-negative ones at distances further away from the senile plates $(45.0 \pm 2.8 \%$ vs. $56.1 \pm 2.2 \%$ respectively, Figure 5B). A similar tendency, but not statistically significative, was found in the advanced stages $(63.3 \pm 1.3 \%$ vs. $58.3 \pm 1.0 \%$ and $36.6 \pm 1.3 \%$ vs. $41.6 \pm 1.1 \%$ respectively, Figure 5B). In the late stages, we did not find any difference in the distribution pattern of microglial cells outside senile plates $(91.4 \pm 2.0 \%$ vs. $95.3 \pm 1.7 \%$ and $2.9 \pm 1.0 \%$ vs. $1.5 \pm 0.9 \%$ respectively). Although our findings suggest that P2X7R-activation promotes the microglial recruitment toward senile plates, in comparison, inside the senile plates, the majority of microglial cells did not express this receptor.

\section{P2X7R Modules the Phagocytic Capacity of Microglia Cells}

To elucidate what role $\mathrm{P} 2 \mathrm{X} 7 \mathrm{R}$ plays on recruited microglial cells inside senile plates, we decided to evaluate the possible role of this receptor in another of the most relevant microglial functions, the phagocytosis. Initially, we decided to use, once again, primary microglial cells cultures. To evaluate phagocytic capacity of cultured microglial cells, we measured the number of fluorescence microspheres phagocyted after them were stimulated with BzATP in the presence or absence of the selective P2X7R antagonists (Figure 6A).

Our results showed that BzATP stimulation reduced the phagocytic ability of microglial cells $(8.9 \pm 0.8$ microspheres per microglial cell treated with PBS vs. $3.8 \pm 0.4$ microspheres per microglial cell treated with BzATP, Figures 6A,B). Interestingly, selective P2X7R antagonists reverted the reduced phagocytic capacity induced by BzATP (6.5 \pm 1.5 microspheres per microglial cell treated with A438072 plus BzATP and $7.1 \pm 0.7$ microspheres per microglial cell treated with GSK 1482160A plus BzATP, Figures 6A,B). As negative phagocytosis control, microglial cells were treated with CytoD, an inhibitor of actin polymerization that blocks more than $90 \%$ of the phagocytosis capacity $(1.3 \pm 0.1$ microspheres per microglial cell treated with Cyto D, Figures 6A,B). Interestingly, the negative effect induced by $\mathrm{P} 2 \mathrm{X} 7 \mathrm{R}$ activation on microglial phagocytic capacity was not modified when cells were LPS-pre-treated $(8.4 \pm 0.6$ microspheres per microglial cell treated with LPS vs. $2.9 \pm 0.8$ microspheres per microglial cell treated with LPS plus BzATP, Supplementary Figure 3). To consolidate these results, in the following step, we decided to administrate fluorescence microspheres i.c. to the hippocampus of P2X7R EGFP mice. After i.c. injection, ${ }^{P 2 X 7 R}$ EGFP mice were daily i.p. treated for 7 days with the P2X7R antagonist GSK 1482160A or vehicle solution before being sacrificed. Hippocampus from ${ }^{\mathrm{P} 2 \mathrm{X} 7 \mathrm{R}} \mathrm{EGFP}$ mice was analyzed by immunofluorescence techniques using anti-EGFP, and anti-Iba-1 antibodies (Figure 6C). Results revealed that in vivo pharmacology P2X7R blockage promoted the phagocytic capacity of the microglial cells (Figure 6D). Interesting, most of the phagocytic microglial cells on vehicletreated mice expressed the P2X7R reporter protein EGFP 

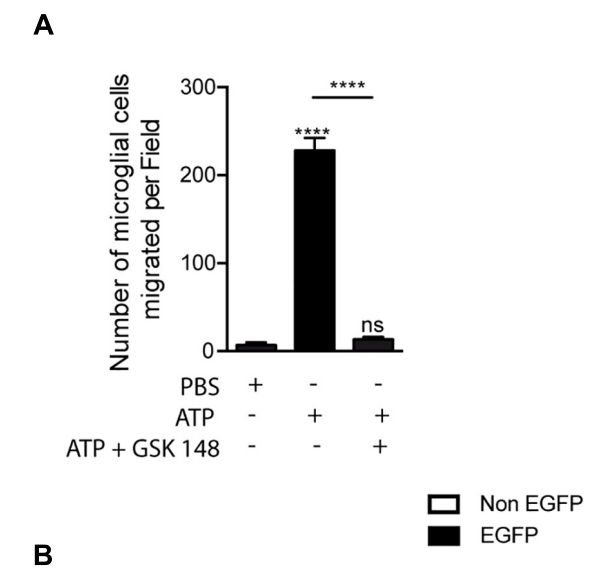

$\%$ microglial cells inside plates
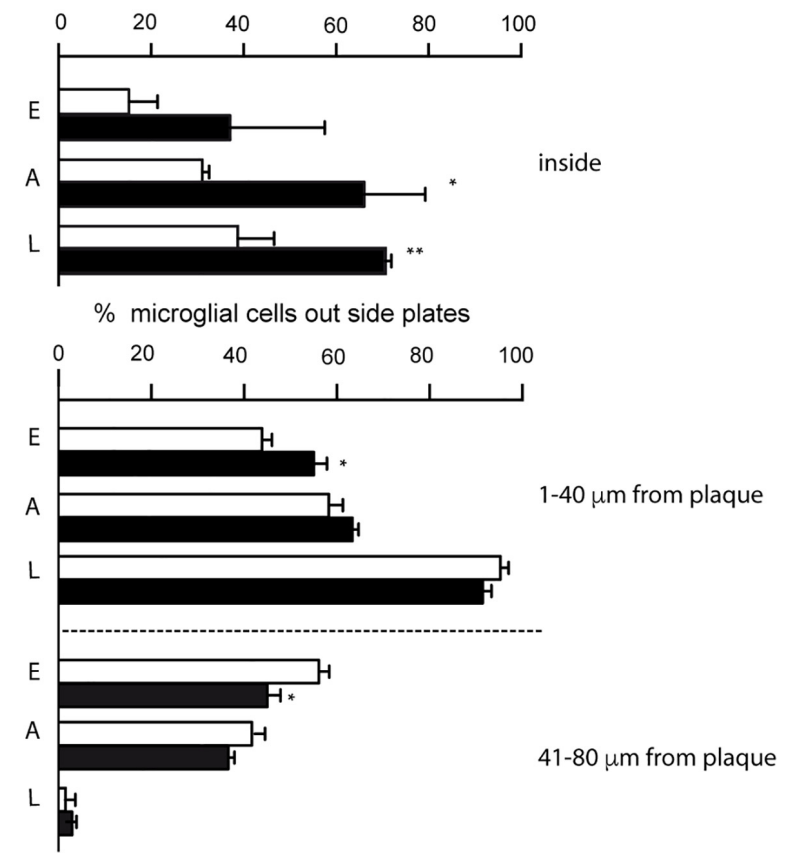

FIGURE 5 | Selective P2X7R activation promotes microglial migration to senile plates. (A) The graph shows the number of cultured microglial cells from the hippocampus of WT mice migrating through trans-well inserts after being stimulated with $1 \mathrm{mM}$ ATP in the presence or absence of $1 \mu \mathrm{M}$ GSK 1482160A. Values represent, at least, the mean \pm s.e.m of 3 independent cultures run in duplicate. ${ }^{* * * *} p<0.0001$ using ANOVA test followed by Bonferroni's tests, ns not statistically significant. (B) Graphs show the number of hippocampal microglial cells expressing (black bars) or not (white bars) the P2X7 receptor reporter protein (EGFP) inside (upper graph) or in the nearness (lower graph) of senile plaques identified P2X7REGFP/J20 mice at early, advanced or late stages ( $n \geq 5$ mice per age; sections $\geq 8$ per mouse; plaques $\geq 15$ per sections). ${ }^{*} p<0.05,{ }^{* *} p<0.01$, using unpaired $t$-test. Data in bar graphs represent mean \pm s.e.m. E meaning early stages, $A$ meaning advances stages and $L$ meaning late stages.

$(81.9 \pm 2.4 \%$ was EGFP-negative vs. $18.1 \pm 2.4 \%$ was EGFPpositive). However, in GSK 1482160A-treated mice, no significant differences were detected between both microglial populations (51.5 $\pm 5.0 \%$ was EGFP-negative vs. $45.5 \pm 5.0 \%$ was EGFPpositive) (Figure 6E). It is worth highlighting that $\mathrm{P} 2 \mathrm{X} 7 \mathrm{R}$ inhibition also caused the EGFP-positive microglial cells to increase their phagocytic capacity, so these cells passed to phagocyte a mean of $0.7 \pm 0.1$ to $1.7 \pm 0.2$ microspheres per cell (Figure 6F). However, the pharmacological blockage of P2X7R did not modify the phagocytic capacity of EGFP-negative cells $(1.6 \pm 0.2$ vehicle vs. $1.5 \pm 0.1$ GSK $1482160 \mathrm{~A})$ (Figure 6F) All these data suggest that P2X7R negatively modulates the microglial phagocyte capacity.

\section{DISCUSSION}

In the present study, we have evaluated the impact of microglial cells expressing P2X7R on FAD progression analyzing the new transgenic mouse model ${ }^{\text {P2X7R }}$ EGFP/J20 mice. In the early stages, when $\mathrm{A} \beta$ peptide begins assembling on detectable extracellular $\beta$-amyloid deposits, but still non-evident microglial proliferation takes place, we did not observe significant changes in the percentage of microglial cells expressing P2X7R. However, at this stage, we found that outside plaques, microglial cells expressing P2X7R were closer to nascent plaques than those non-expressing this receptor. On the other hand, both in advanced and late stages, when J20 mice experience microgliosis and an evident cognitive and motor impairments (Mucke et al., 2000), significant increases in P2X7R expression levels and in the percentage of P2X7R expressing microglial cells were detected. Furthermore, at both stages, although P2X7Rexpressing microglial cells were mostly found inside the senile plaques, this microglial population was not the most abundant, either inside the senile plaques or in the whole hippocampus. We also found a significant reduction in the number of neuronal cells transcribing P2X7R in the early and advanced, but not in the late stages.

As observed in J20 mice, we detected in brain samples from $\mathrm{AD}$ patients, both a significant increase of $\mathrm{P} 2 \mathrm{X} 7 \mathrm{R}$ expression levels and a preferred location of microglial cells expressing P2X7R inside senile plaques, but this was not, once again, the most abundant microglial population at this location. Our data confirm that P2X7R mediated signaling is increased in microglial cells on $\mathrm{AD}$, as previously reported by other groups (Parvathenani et al., 2003; McLarnon et al., 2006; Lee et al., 2011). However, on these works did not identify the factors causing the increased P2X7R expression in microglial cells or what consequences had on microglial functionality.

It is well known that ATP-signaling via P2X7R regulates different microglial functions. It is also reported that ATPinduced morphological changes related with their migratory ability, allowing them rapidly to migrate toward the injury (Davalos et al., 2005), in an ATP-induced ATP-release dependent mechanism (Dou et al., 2012). Our in vitro studies confirmed that ATP promotes the microglial mobility by P2X7R activation. Furthermore, using ${ }^{\mathrm{P} 2 \mathrm{X} 7 \mathrm{R}} \mathrm{EGFP} / \mathrm{J} 20$ mice, we have demonstrated that microglial cells expressing P2X7R migrate more quickly toward the extracellular $\beta$-amyloid deposits than those non-expressing this receptor. These results suggest that the enrichment of P2X7R-expressing microglial cells around $\beta$-amyloid deposits observed in the last stages of $\mathrm{AD}$ by other 

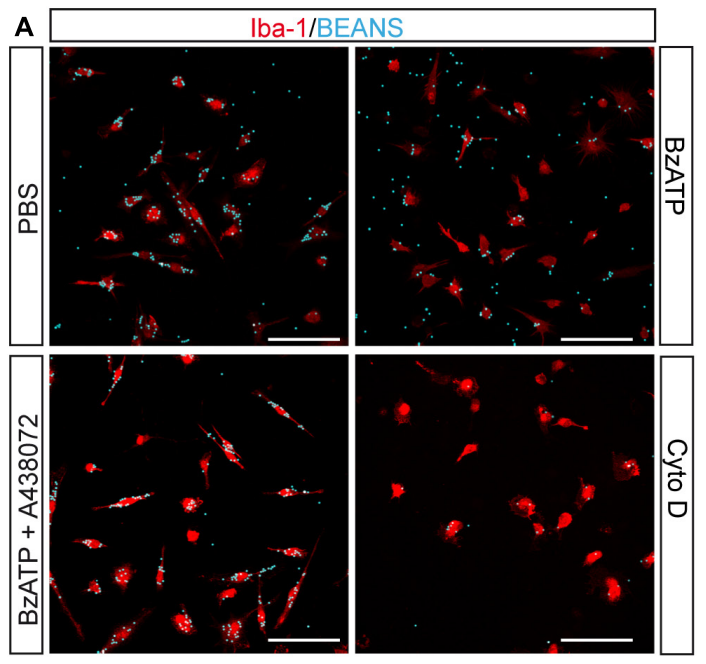

\section{B}
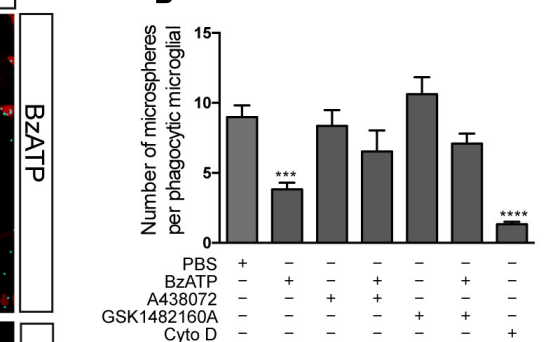

D
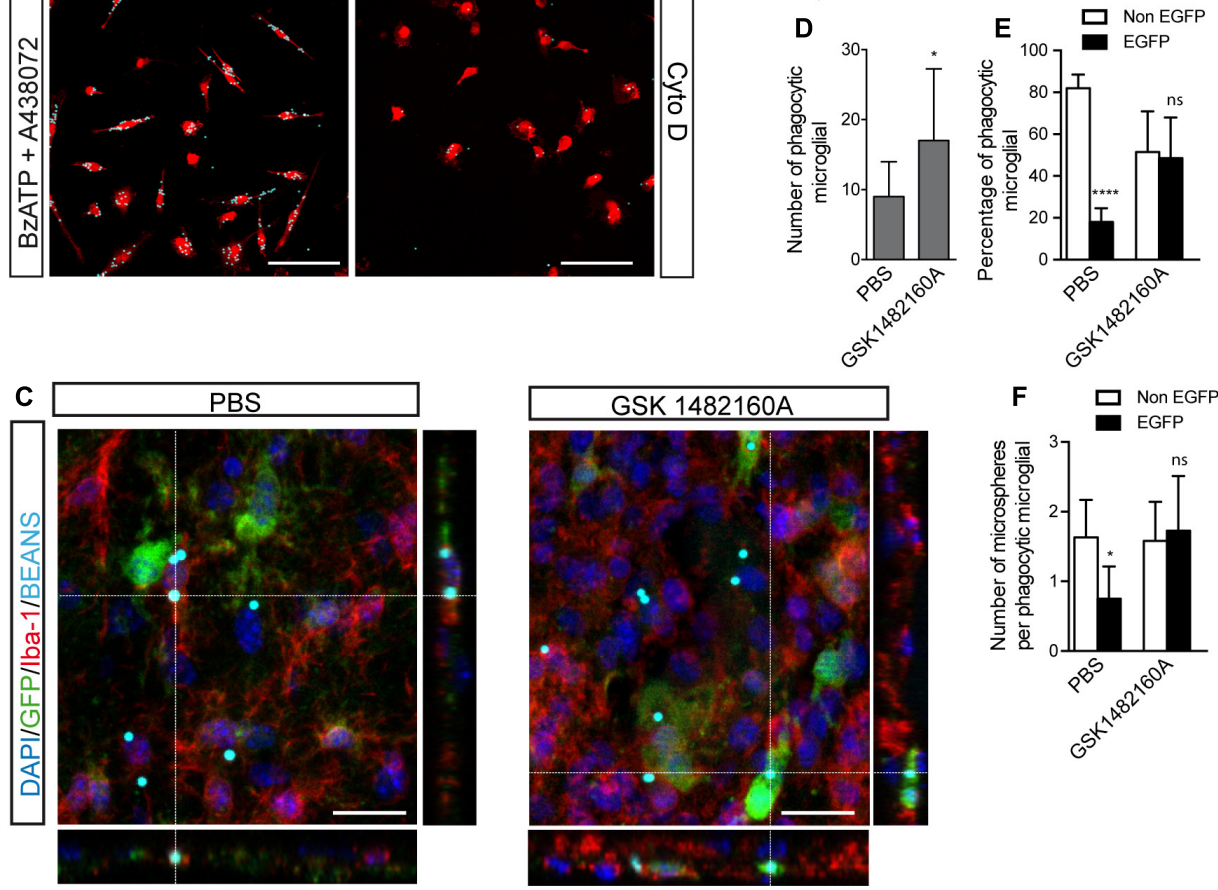

FIGURE 6 | Selective P2X7R inhibition promotes microglial phagocytosis. (A) Representative fluorescence micrographs of cultured microglial cells from the hippocampus of WT mice identified using antibodies against the microglial marker lba-1 (red) uptaking fluorescence microparticles (cyan) after stimulated with $300 \mu \mathrm{M}$ BzATP in presence or absence of the selective P2X7R antagonists $10 \mu \mathrm{M}$ A438072 or $1 \mu \mathrm{M}$ GSK 1482160A. In some cases, the cultured microglial cells were treated with $10 \mu \mathrm{M}$ cytochalasin D (CytoD) as a negative control. (B) The graph shows the number of phagocyted microfluorescent particles per microglial cell under different experimental conditions. Values represent, at least, the mean \pm s.e.m of 4 independent cultures run in duplicate. ${ }^{* * *} p<0.001$ and ${ }^{* * * *} p<0.0001$ using ANOVA test followed by Bonferroni's tests. (C) Representative confocal images and its corresponding orthogonal views of hippocampal sections from 6 months-old P2X7REGFP mice intraperitoneally GSK 1482160A-treated for 7 days after intracranial administration of fluorescent microspheres to the hippocampus. Dashed lines represent the locations where orthogonal views were obtained. Sections were stained with antibodies against EGFP (green), microglial marker lba-1 (red), nuclear marker DAPI (blue), being microspheres visualized in cyan. Scale bar: $50 \mu \mathrm{m}$. (D) The graph shows the number of microglial cells uptaking fluorescent microspheres on PBS- or GSK 1482160A-treated P2X7REGFP mice ( $n \geq 4$ mice per treatment; sections $\geq 8$ per mouse). (E) The graph shows the percentage of phagocytic microglial cells expressing (black) or not (white) the P2X7 receptor reporter protein EGFP on PBS- or GSK $1482160 A$-treated P2X7REGFP mice $(n \geq 4$ mice per treatment; sections $\geq 8$ per mouse). (F) The graph shows the number of incorporated fluorescent microspheres by microglial cells expressing (black) or not (white) the P2X7 receptor reporter protein EGFP on PBS- or GSK 1482160A-treated P2X7REGFP mice ( $n \geq 4$ mice per treatment; sections $\geq 8$ per mouse). ${ }^{*} p<0.05,{ }^{* * *} p<0.0001$, using unpaired $t$-test, ns not statistically significant. Data in bar graphs represent mean \pm s.e.m.

authors (Parvathenani et al., 2003; McLarnon et al., 2006; Lee et al., 2011) may result from the increased migratory capacity of these cells by the increase of P2X7R expression levels. This hypothesis is in accordance with the fact that the upregulation of P2X7R on microglial cells increases parallel to the incidence of senile plaques in the brain (Lee et al., 2011). Moreover, since microglial $\mathrm{P} 2 \mathrm{X} 7 \mathrm{R}$ activation also triggers the cytokines release (Di Virgilio et al., 2017), P2X7R activation on migratory microglial would favor, in turn, the recruitment of microglial cells toward the plaques. In this way, we found that outside of extracellular $\beta$-amyloid deposits, the non-positive P2X7R microglial cells present delayed recruitment toward them compared to microglial cells expressing P2X7R.

It has also been reported that cytoskeleton changes in microglial cells caused by ATP-induced P2X7R activation, reduce their phagocytic capacity (Fang et al., 2009). Accordingly, downregulation of $\mathrm{P} 2 \mathrm{X} 7 \mathrm{R}$ using small RNA interference favors the $\mathrm{A} \beta$ peptide phagocytosis (Ni et al., 2013). Here, using both in vitro and in vivo approaches, we found that selective pharmacological $\mathrm{P} 2 \mathrm{X} 7 \mathrm{R}$ inhibition promotes 
microglial phagocytosis. In agreement with an inverse relationship between P2X7R expression and microglial phagocytic capacity, we discovered that most microglial cells in the senile plaques did not express P2X7R. It is worth highlighting that, although there was a higher number of microglial cells inside senile plaques in the late, rather than in the advanced stages, the percentage of P2X7R positive microglial cells inside extracellular $A \beta$ deposits is similar in both phases. Considering that microglial recruitment toward senile plaques remains over $\mathrm{AD}$ progression, one possible explanation is that, after promotes migration of microglial cells to senile plaques, once they reach the plaque, $\mathrm{P} 2 \mathrm{X} 7 \mathrm{R}$ expression is decreased favoring the $\mathrm{A} \beta$ peptide phagocytosis. Supporting this hypothesis, we found that the low phagocytosis capacity detected in P2X7R-expressing microglial cells increases once the receptor is pharmacologically blocked. However, additional experiments should be made to confirm this hypothesis.

Over recent years, there has been an active debate in the field about the preferential expression of P2X7R on neural cells (Illes et al., 2017; Miras-Portugal et al., 2017). These opposing points of view are mainly due to that fact that some groups found P2X7R in neurons (Miras-Portugal et al., 2017), whereas other groups detected it mainly in glial cells, especially in microglial cells, but not in neurons (Illes et al., 2017). In the present work, using a well-characterized P2X7R reporter

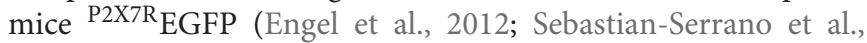
2016), we found that, at hippocampal level, under physiological conditions, P2X7R is mainly transcribed in neurons, expressing on the nerve endings from those granular neurons on dentate gyrus that project their axons toward the CA3 region, as previously reported (Sebastian-Serrano et al., 2016). However, under pathological conditions where neuroinflammation causes microglial proliferation and activation, as occurs in J20 mice at advanced and late stages or in LPS treated mice, the P2X7R distribution pattern changes, decreasing its transcription on neurons and increasing in microglial cells. These results suggest that neuroinflammation regulates the expression of P2X7R both in neurons and in glial cells. In agreement with this idea it has been reported that P2X7R pharmacological blockage or its downregulation by small RNA interference attenuated LPS-induced neuroinflammation by avoiding the microglial activation and the subsequence inflammation (Lu et al., 2013), and decreased microglial proliferation (Bianco et al., 2006). Since proinflammatory cytokines released by P2X7R may cause the receptor upregulation, this positive feedback loop might promote and maintain, over time, an exacerbating microglial response contributing in this way to the adverse effects associated with neuroinflammation (Mosher and WyssCoray, 2014). Supporting this hypothesis, a close relationship has been detected between P2X7R upregulation in microglial cells and synaptic toxicity on AD (Lee et al., 2011). In this sense, it is worth noting that the compression of brain tissue by the extracellular $\mathrm{A} \beta$ deposits may cause a mechanical ATP release (Burnstock et al., 2011), which, in addition to favoring the migration of $\mathrm{P} 2 \mathrm{X} 7 \mathrm{R}$-expressing microglial cells toward these deposits, may also promote a sustained activation of neuronal P2X7R. Since the persistent activation of P2X7R on neurons by high extracellular ATP levels may also lead to compromise the cellular viability, the reduction of P2X7R transcription observed in neurons both the early and advanced stages, may be an adaptive physiological response to avoid or at least reduce the neuronal loss associated to $\mathrm{AD}$. In this way, the loss of this regulatory mechanism might be contributing to the neuronal loss detected in the late stages of $\mathrm{AD}$.

\section{CONCLUSION}

We found that neuroinflammation associated with $\mathrm{AD}$ induces a change in the P2X7R distribution pattern, increasing its expression on microglial cells at advanced and late stages of $\mathrm{AD}$, when there is evident microgliosis. P2X7R activation improves the migratory faculty of microglial cells to senile plaques but decreases their phagocytic capacity. Additionally, we found a significant reduction of P2X7R transcription in neuronal cells at the early and advanced, but not at the late stages of AD. Because different studies have demonstrated that both pharmacological inhibition or the selective downregulation of P2X7R significantly improve behavioral alterations and reduce the incidence and size of senile plaques in the early and advanced stages of AD (Diaz-Hernandez et al., 2012; Chen et al., 2014; Martin et al., 2018), the results presented here provide new pieces of evidences indicating that this therapeutic approach may also be useful in the late stages of the disease.

\section{ETHICS STATEMENT}

This study was carried out in accordance with the recommendations of 'Ethical Committees of the Netherlands Brain Bank with written informed consent from all subjects. All subjects gave written informed consent in accordance with the Declaration of Helsinki. The protocol was approved by the Ethical Committees of the Netherlands Brain Bank.' This study was carried out in accordance with the recommendations of 'International Council for the Laboratory Animal Science'. The protocol was approved by the Committee of Animal Experiments of the Complutense University of Madrid and the Environmental Counseling of the Comunidad de Madrid, Spain.

\section{AUTHOR CONTRIBUTIONS}

CM-F treated and processed the mice generating and analyzing the samples, participated in experimental design, and contributed to the interpretation of the data. CDL contributed the processing and analyzing of samples and contributed to the interpretation of the data. AS-S, LdD-G, CB, and LB revised the manuscript 
and helped in the interpretation of data. $\mathrm{MD}-\mathrm{H}$ participated in the experimental design, in the interpretation of the results, wrote the manuscript, and also provided the financial support for the work.

\section{FUNDING}

This work was supported by funding from the Spanish Ministry of Science and Education BFU2012-31195 (to MD-H), SAF201782436R (to LB), European Union project H2020-MSCA-ITN2017 number 766124 (to MD-H), and from Universidad Complutense of Madrid (UCM)-Santander Central Hispano Bank PR41/17-21014 (to MD-H). CM-F had an FPI pre-doctoral fellowship associated to BFU2012-31195. CDL and CB were hired by H2020-MSCA-ITN-2017 number 766124. AS-S was hired by BFU2012-31195 grant and LdD-G had an UCM pre-doctoral

\section{REFERENCES}

Avila, J. (2006). Tau protein, the main component of paired helical filaments. J. Alzheimers Dis. 9, 171-175. doi: 10.3233/JAD-2006-9S320

Bianco, F., Ceruti, S., Colombo, A., Fumagalli, M., Ferrari, D., Pizzirani, C., et al. (2006). A role for P2X7 in microglial proliferation. J. Neurochem. 99, 745-758. doi: $10.1111 / j .1471-4159.2006 .04101 . x$

Burnstock, G., Fredholm, B. B., and Verkhratsky, A. (2011). Adenosine and ATP receptors in the brain. Curr. Top. Med. Chem. 11, 973-1011. doi: 10.2174/ 156802611795347627

Chen, X., Hu, J., Jiang, L., Xu, S., Zheng, B., Wang, C., et al. (2014). Brilliant Blue $\mathrm{G}$ improves cognition in an animal model of Alzheimer's disease and inhibits amyloid-beta-induced loss of filopodia and dendrite spines in hippocampal neurons. Neuroscience 279, 94-101. doi: 10.1016/j.neuroscience.2014.08.036

Damani, M. R., Zhao, L., Fontainhas, A. M., Amaral, J., Fariss, R. N., and Wong, W. T. (2011). Age-related alterations in the dynamic behavior of microglia. Aging Cell 10, 263-276. doi: 10.1111/j.1474-9726.2010.00660.x

Davalos, D., Grutzendler, J., Yang, G., Kim, J. V., Zuo, Y., Jung, S., et al. (2005). ATP mediates rapid microglial response to local brain injury in vivo. Nat. Neurosci. 8, 752-758. doi: $10.1038 / \mathrm{nn} 1472$

de Diego Garcia, L., Sebastian-Serrano, A., Hernandez, I. H., Pintor, J., Lucas, J. J., and Diaz-Hernandez, M. (2018). The regulation of proteostasis in glial cells by nucleotide receptors is key in acute neuroinflammation. FASEB J. 32, 3020-3032. doi: 10.1096/fj.201701064RR

Delarasse, C., Auger, R., Gonnord, P., Fontaine, B., and Kanellopoulos, J. M. (2011). The purinergic receptor $\mathrm{P} 2 \mathrm{X} 7$ triggers alpha-secretase-dependent processing of the amyloid precursor protein. J. Biol. Chem. 286, 2596-2606. doi: 10.1074/jbc. M110.200618

Di Virgilio, F., Dal Ben, D., Sarti, A. C., Giuliani, A. L., and Falzoni, S. (2017). The P2X7 receptor in infection and inflammation. Immunity 47, 15-31. doi: 10.1016/j.immuni.2017.06.020

Diaz-Hernandez, J. I., Gomez-Villafuertes, R., Leon-Otegui, M., HontecillasPrieto, L., Del Puerto, A., Trejo, J. L., et al. (2012). In vivo P2X7 inhibition reduces amyloid plaques in Alzheimer's disease through GSK3beta and secretases. Neurobiol. Aging 33, 1816-1828. doi: 10.1016/j.neurobiolaging.2011. 09.040

Dou, Y., Wu, H. J., Li, H. Q., Qin, S., Wang, Y. E., Li, J., et al. (2012). Microglial migration mediated by ATP-induced ATP release from lysosomes. Cell Res. 22, 1022-1033. doi: $10.1038 / \mathrm{cr} .2012 .10$

Engel, T., Gomez-Villafuertes, R., Tanaka, K., Mesuret, G., Sanz-Rodriguez, A., Garcia-Huerta, P., et al. (2012). Seizure suppression and neuroprotection by targeting the purinergic $\mathrm{P} 2 \mathrm{X} 7$ receptor during status epilepticus in mice. FASEB J. 26, 1616-1628. doi: 10.1096/fj.11-196089

Fang, K. M., Yang, C. S., Sun, S. H., and Tzeng, S. F. (2009). Microglial phagocytosis attenuated by short-term exposure to exogenous ATP through P2X receptor action. J. Neurochem. 111, 1225-1237. doi: 10.1111/j.1471-4159.2009.06409.x fellowship supervised by MD-H. This work was supported in part by FEDER.

\section{ACKNOWLEDGMENTS}

We would like to thank Dra Maria Teresa de Frailes-Alvaro for her help in providing us with the selective P2X7R antagonist GSK 1482160A (from GlaxoSmithKline, Madrid, Spain).

\section{SUPPLEMENTARY MATERIAL}

The Supplementary Material for this article can be found online at: https://www.frontiersin.org/articles/10.3389/fncel. 2019.00143/full\#supplementary-material

Gahtan, E., and Overmier, J. B. (1999). Inflammatory pathogenesis in Alzheimer's disease: biological mechanisms and cognitive sequeli. Neurosci. Biobehav. Rev. 23, 615-633. doi: 10.1016/S0149-7634(98)00058-X

Hsiao, K., Chapman, P., Nilsen, S., Eckman, C., Harigaya, Y., Younkin, S., et al. (1996). Correlative memory deficits, Abeta elevation, and amyloid plaques in transgenic mice. Science 274, 99-102. doi: 10.1126/science.274.5284.99

Illes, P., Khan, T. M., and Rubini, P. (2017). Neuronal P2X7 receptors revisited: do they really exist? J. Neurosci. 37, 7049-7062. doi: 10.1523/JNEUROSCI.310316.2017

Koenigsknecht-Talboo, J., Meyer-Luehmann, M., Parsadanian, M., GarciaAlloza, M., Finn, M. B., Hyman, B. T., et al. (2008). Rapid microglial response around amyloid pathology after systemic anti-Abeta antibody administration in PDAPP mice. J. Neurosci. 28, 14156-14164. doi: 10.1523/JNEUROSCI.4147-08. 2008

Lee, H. G., Won, S. M., Gwag, B. J., and Lee, Y. B. (2011). Microglial P2X(7) receptor expression is accompanied by neuronal damage in the cerebral cortex of the APPswe/PS1dE9 mouse model of Alzheimer's disease. Exp. Mol. Med. 43, 7-14. doi: 10.3858/emm.2011.43.1.001

Leon-Otegui, M., Gomez-Villafuertes, R., Diaz-Hernandez, J. I., DiazHernandez, M., Miras-Portugal, M. T., and Gualix, J. (2011). Opposite effects of P2X7 and P2Y2 nucleotide receptors on alpha-secretasedependent APP processing in Neuro-2a cells. FEBS Lett. 585, 2255-2262. doi: 10.1016/j.febslet.2011.05.048

Ling, Y., Morgan, K., and Kalsheker, N. (2003). Amyloid precursor protein (APP) and the biology of proteolytic processing: relevance to Alzheimer's disease. Int. J. Biochem. Cell Biol. 35, 1505-1535. doi: 10.1016/S1357-2725(03)00133-X

Lu, K., Wang, J., Hu, B., Shi, X., Zhou, J., Tang, Y., et al. (2013). Brilliant blue $G$ attenuates lipopolysaccharide-mediated microglial activation and inflammation. Neural Regen. Res. 8, 599-608. doi: 10.3969/j.issn.1673-5374. 2013.07.003

Martin, E., Amar, M., Dalle, C., Youssef, I., Boucher, C., Le Duigou, C., et al. (2018). New role of P2X7 receptor in an Alzheimer's disease mouse model. Mol. Psychiatry 24, 108-125. doi: 10.1038/s41380-0180108-3

McLarnon, J. G., Ryu, J. K., Walker, D. G., and Choi, H. B. (2006). Upregulated expression of purinergic P2X(7) receptor in Alzheimer disease and amyloidbeta peptide-treated microglia and in peptide-injected rat hippocampus. J. Neuropathol. Exp. Neurol. 65, 1090-1097. doi: 10.1097/01.jnen.0000240470. 97295.d3

Miras-Portugal, M. T., Sebastian-Serrano, A., De Diego Garcia, L., and DiazHernandez, M. (2017). Neuronal P2X7 receptor: involvement in neuronal physiology and pathology. J. Neurosci. 37, 7063-7072. doi: 10.1523/ JNEUROSCI.3104-16.2017

Mosher, K. I., and Wyss-Coray, T. (2014). Microglial dysfunction in brain aging and Alzheimer's disease. Biochem. Pharmacol. 88, 594-604. doi: 10.1016/j.bcp. 2014.01.008 
Mucke, L., Masliah, E., Yu, G. Q., Mallory, M., Rockenstein, E. M., Tatsuno, G., et al. (2000). High-level neuronal expression of abeta 1-42 in wild-type human amyloid protein precursor transgenic mice: synaptotoxicity without plaque formation. J. Neurosci. 20, 4050-4058. doi: 10.1523/JNEUROSCI.20-11-04050. 2000

Ni, J., Wang, P., Zhang, J., Chen, W., and Gu, L. (2013). Silencing of the P2X(7) receptor enhances amyloid-beta phagocytosis by microglia. Biochem. Biophys. Res. Commun. 434, 363-369. doi: 10.1016/j.bbrc.2013.03.079

Parvathenani, L. K., Tertyshnikova, S., Greco, C. R., Roberts, S. B., Robertson, B., and Posmantur, R. (2003). P2X7 mediates superoxide production in primary microglia and is up-regulated in a transgenic mouse model of Alzheimer's disease. J. Biol. Chem. 278, 13309-13317. doi: 10.1074/jbc.M209478200

Paxinos, G., and Franklin, K. B. J. (2001). The Mouse Brain in Stereotaxic Coordinates, 2nd Edn. San Diego, CA: Academic Press.

Price, D. L., and Sisodia, S. S. (1998). Mutant genes in familial Alzheimer's disease and transgenic models. Annu. Rev. Neurosci. 21, 479-505. doi: 10.1146/annurev. neuro.21.1.479

Radde, R., Bolmont, T., Kaeser, S. A., Coomaraswamy, J., Lindau, D., Stoltze, L., et al. (2006). Abeta42-driven cerebral amyloidosis in transgenic mice reveals early and robust pathology. EMBO Rep. 7, 940-946. doi: 10.1038/sj.embor. 7400784

Ryu, J. K., and Mclarnon, J. G. (2008). Block of purinergic P2X(7) receptor is neuroprotective in an animal model of Alzheimer's disease. Neuroreport 19, 1715-1719. doi: 10.1097/WNR.0b013e3283179333

Sanz, J. M., Chiozzi, P., Ferrari, D., Colaianna, M., Idzko, M., Falzoni, S., et al. (2009). Activation of microglia by amyloid \{beta\} requires P2X7 receptor expression. J. Immunol. 182, 4378-4385. doi: 10.4049/jimmunol.0803612

Sanz, J. M., Falzoni, S., Rizzo, R., Cipollone, F., Zuliani, G., and Di Virgilio, F. (2014). Possible protective role of the 489C $>$ T P2X7R polymorphism in Alzheimer's disease. Exp. Gerontol. 60, 117-119. doi: 10.1016/j.exger.2014.10.009

Sebastian-Serrano, A., Engel, T., De Diego-Garcia, L., Olivos-Ore, L. A., Arribas-Blazquez, M., Martinez-Frailes, C., et al. (2016). Neurodevelopmental alterations and seizures developed by mouse model of infantile hypophosphatasia are associated with purinergic signalling deregulation. Hum. Mol. Genet. 25, 4143-4156. doi: 10.1093/hmg/ ddw248

Selkoe, D. J. (2001). Alzheimer's disease: genes, proteins, and therapy. Physiol. Rev. 81, 741-766. doi: 10.1152/physrev.2001.81. 2.741

Serrano-Pozo, A., Gomez-Isla, T., Growdon, J. H., Frosch, M. P., and Hyman, B. T. (2013). A phenotypic change but not proliferation underlies glial responses in Alzheimer disease. Am. J. Pathol. 182, 2332-2344. doi: 10.1016/j.ajpath.2013.02.031

Solito, E., and Sastre, M. (2012). Microglia function in Alzheimer's disease. Front. Pharmacol. 3:14. doi: 10.3389/fphar.2012.00014

Conflict of Interest Statement: The authors declare that the research was conducted in the absence of any commercial or financial relationships that could be construed as a potential conflict of interest.

Copyright (c) 2019 Martínez-Frailes, Di Lauro, Bianchi, de Diego-García, SebastiánSerrano, Boscá and Díaz-Hernández. This is an open-access article distributed under the terms of the Creative Commons Attribution License (CC BY). The use, distribution or reproduction in other forums is permitted, provided the original author(s) and the copyright owner(s) are credited and that the original publication in this journal is cited, in accordance with accepted academic practice. No use, distribution or reproduction is permitted which does not comply with these terms. 